\title{
Radio Frequency Identification and Its Application in E-Commerce
}

\author{
Witold Bahr \\ Aston University, UK \\ Brian Price \\ Aston University, UK

\section{INTRODUCTION}

This chapter presents Radio Frequency Identification (RFID), which is one of the Automatic Identification and Data Capture (AIDC) technologies (Wamba and Boeck, 2008) and discusses the application of RFID in E-Commerce. Firstly RFID is defined and the tag and reader components of the RFID system are explained. Then historical context of RFID is briefly discussed. Next, RFID is contrasted with other AIDC technologies, especially the use of barcodes which are commonly applied in E-Commerce. Lastly, RFID applications in E-Commerce are discussed with the focus on achievable benefits and obstacles to successful applications of RFID in E-Commerce, and ways to alleviate them.

\section{RADIO FREQUENCY IDENTIFICATION (RFID)}

RFID is an abbreviation for Radio Frequency Identification and as the name implies it is a technology that transmits coded information sets through radio waves. Information is transmitted between RFID tags (also called transponders) and readers (or interrogators) (Hunt et al., 2007). The information flow in a basic RFID system is presented in Figure 1 (based on Dua and Meyers, 2007). The tag receives a radio signal from the reader. The tag is activated and sends back the data to the reader. The collected information is passed on to RFID middleware for processing, for use in business applications. Each tag consists of unique identification information about the item to which it is attached, e.g. item ID, date of production, shipping detail, expiry date, etc. depending on the intended uses (Dua and Meyers, 2007).

An RFID system is defined as an "integrated collection of components that implement an RFID solution" (Lahiri, 2005, p. 7) and is also referenced as RFID infrastructure (Banks, 2007). There is a differ-

Figure 1. Basic components of RFID system and information flow

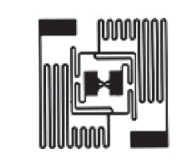

Asset identifier RFID tag
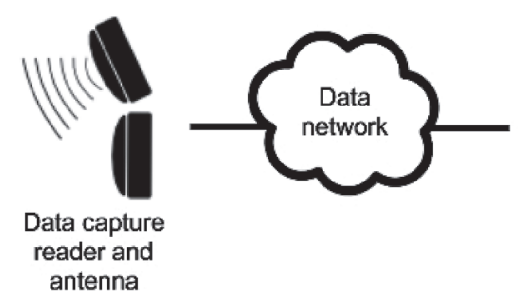

antenna
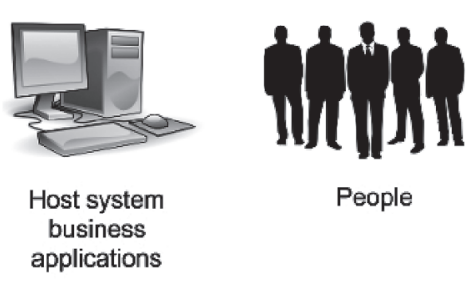

People

DOI: 10.4018/978-1-4666-9787-4.ch130 
ence of opinion among authors regarding what constitutes the RFID system. Five different propositions of what constitutes the RFID system are presented in Figure 2. It can be deducted from Figure 2 that an RFID system in its most basic form consists of a tag (transponder) and a reader (interrogator), which is the view put forward by Finkenzeller (2010).

\section{RFID TAGS}

\section{Elements of RFID Tag}

An RFID tag is defined by Lahiri $(2005$, p. 9) as a "device that can store and transmit data to a reader in a contactless manner using radio waves". Although RFID tags come in different shapes and sizes, as illustrated by Figure 3, they all have in common three essential components (Banks, 2007; Finkenzeller, 2010): antenna (coupling element), integrated circuit (chip), printed circuit board/substrate (housing). Figure 4 illustrates the three core elements of an RFID tag. Additionally, some tags may have their own power source (i.e. battery) and/or sensory elements.

The antenna in an RFID tag transmits and receives radio waves and facilitates the communication with the reader, and when it is used as a coupling element, it draws energy from the reader and energises the tag for communication (Lahiri, 2005). Antenna determines the size of the RFID tag (Banks, 2007).

The integrated circuit or chip is another essential component of the RFID tag and can be described as the tag's "brain" (Banks, 2007). The chip consists of several elements: modulator, power control, clock extractor, logic, and memory (Lahiri, 2005). Logic and memory elements constitute the "brain" part of the chip, as they provide implementation of communication protocol and storage for data, respectively (Lahiri, 2005). Depending on the complexity of the tag the integrated circuit can only send its unique identifier or it may send more data, for example data collected from peripheral components (Banks, 2007).

The printed circuit board, substrate or housing are the structural elements that hold the various components of the RFID tag together (Banks, 2007). The function of the housing is to provide protection to the chip and antenna to allow for optimal performance (Finkenzeller, 2010). Materials used in providing the substrate/housing for RFID tags come in a wide range of options, from adhesive labels, flexible inlays through to hard plastic enclosures. Figures 4 and 5 provide examples of such different types of materials and configurations.

Figure 2. Five views on elements of RFID system

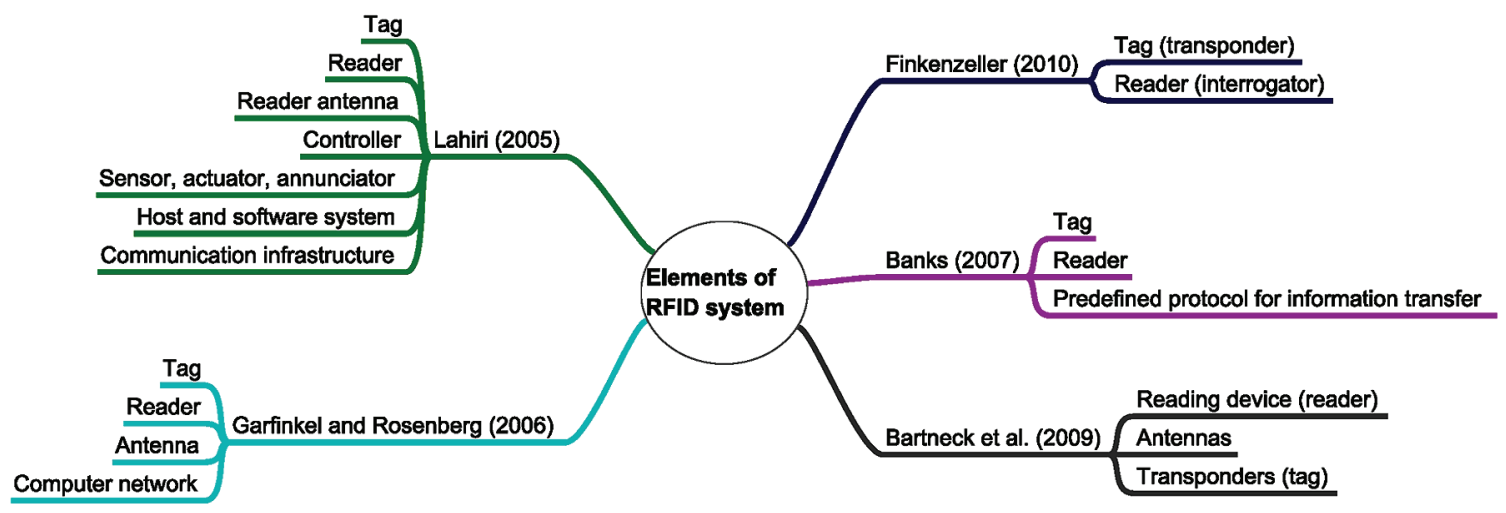


Figure 3. RFID tags come in different shapes and sizes

Source: Arnall (2007).

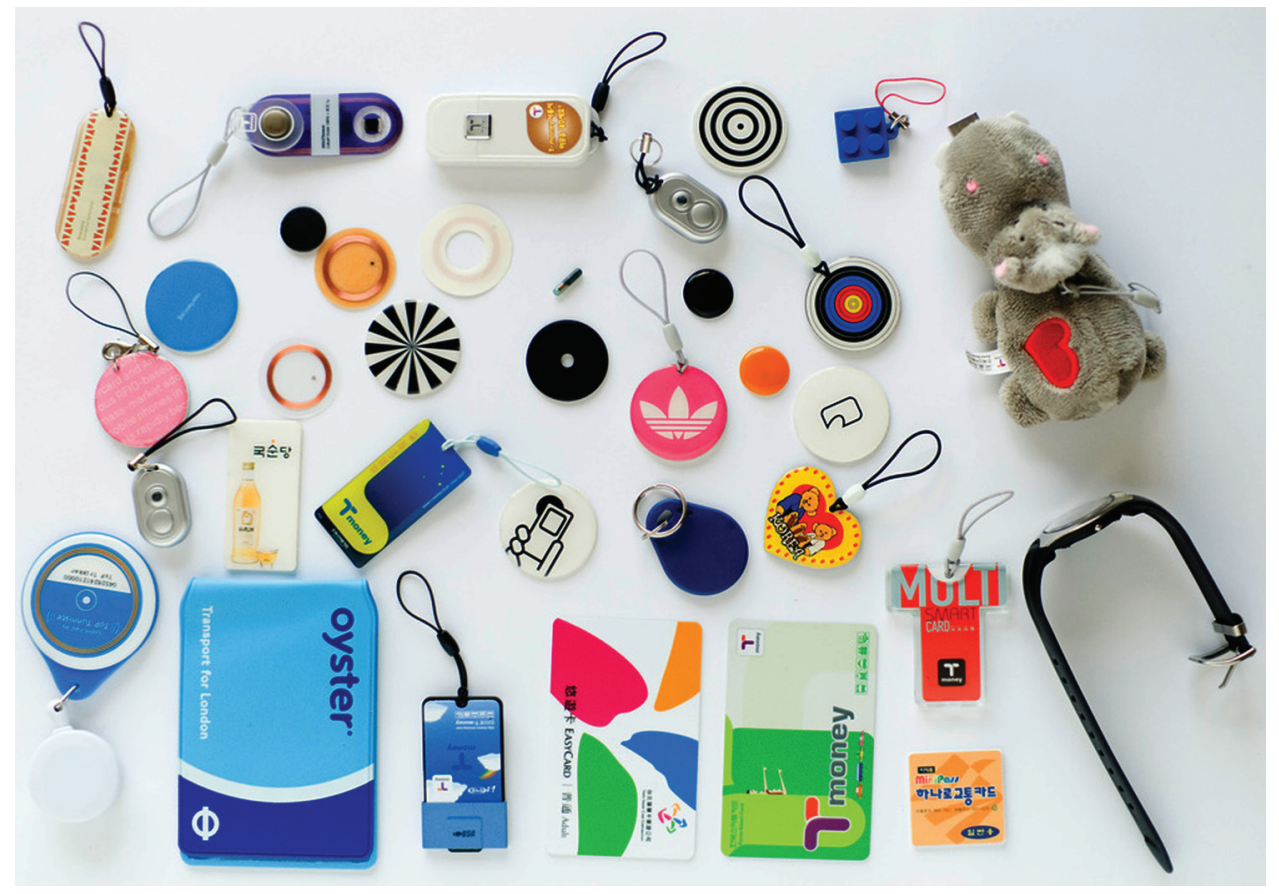

Figure 4. RFID tag elements

Based on Finkenzeller (2010).

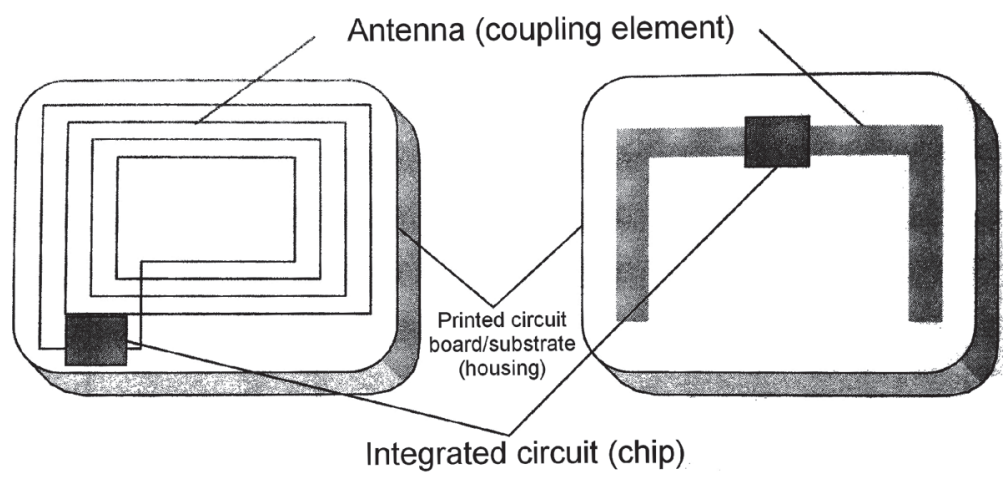

\section{Types of RFID Tags}

RFID tags can be classified in two different ways. Firstly, by the type of power supply that is used to activate the chip: active, passive, and semi-passive; and secondly by the type of frequency used: LF (low frequency), HF (high frequency) and UHF (ultra-high frequency). Figure 5 shows this classification and provides examples of tags from different producers in each category.

Active tags have an onboard power supply (i.e. battery) and may also include elements for performing specialised tasks (i.e. sensory elements) (Lahiri, 2005). Active tags use their own power supply to support communication with the reader. Use of onboard power results in achieving longer reading range and increased readability in harsh environments (Banks, 2007). Additionally, if tag has sensory elements 
Figure 5. Types of RFID tags classified by power supply and frequency

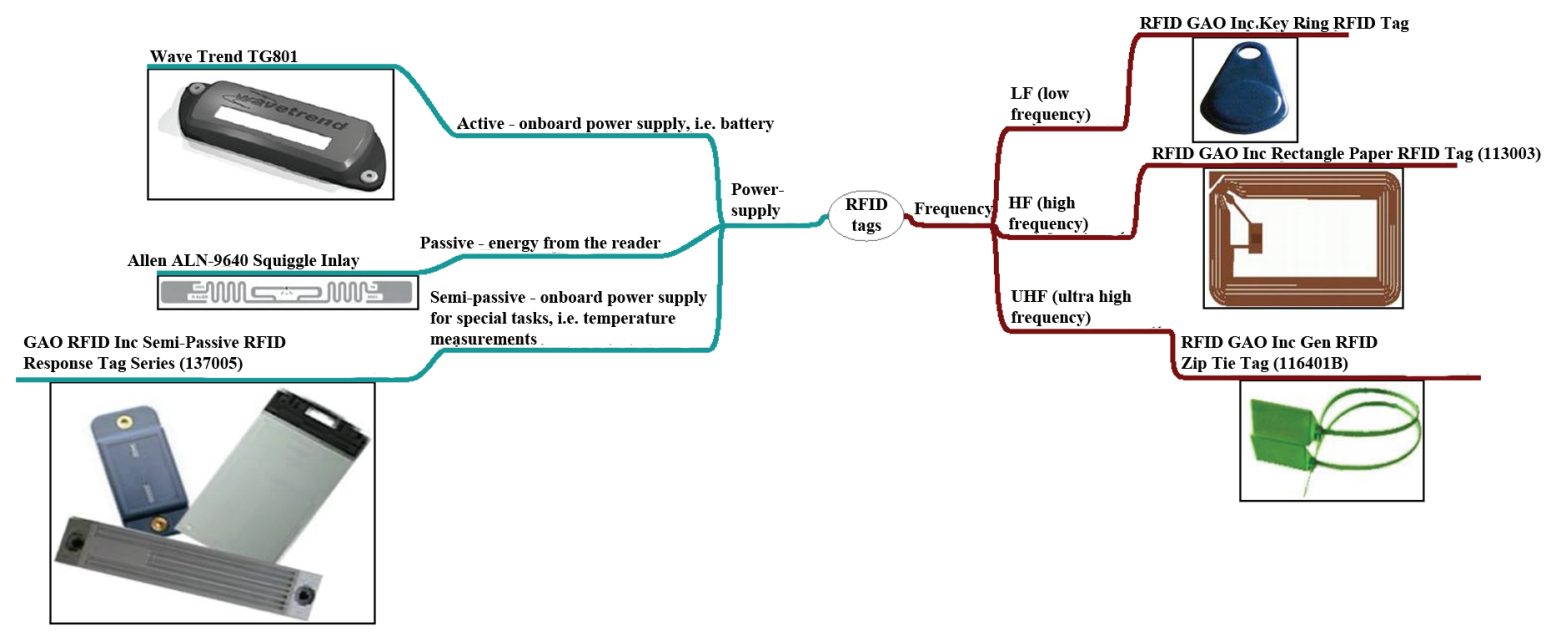

to measure environmental factors like such as temperature, humidity or positioning system, they are also enabled by the onboard power supply (Lahiri, 2005). The power supply of the active tag is limited by the battery capacity, hence in order to extend operational life of the tag it works in so called beacon mode (Banks, 2007). A tag operating in beacon mode sends signals at regular intervals, this means that the more frequent the interval the faster battery depletion. Due to the use of an onboard battery, active tags are the most expensive type of tag and tend to be more bulky that passive tags, as shown in Figure 5. Active tags are commonly used in real-time location systems (Ni et al., 2004) or harsh environments (Banks, 2007) such as construction sites or container ports.

Passive tags don't have onboard power sources and are powered by means of reflected energy from the reader (Dua \& Meyers, 2007; Hunt et al.,2007). As a result passive tags have a relatively simple construction and their price is significantly lower than active tags (Lahiri, 2005). Additionally, passive tags may take on very thin forms such as inlays (see Figure 5) or adhesive labels. However their form makes them more susceptible to changes in magnetic field in close proximity to the tag, which may negatively affect their readability (Banks, 2007). Passive tags are deployed for tracking in RFID implementations where high volume of tags are required, for example: libraries, supply chains etc. (Hunt et al., 2007).

Semi-passive tags, also called battery-assisted tags, use an onboard power supply, but do not use it to assist in communication with the reader (Hunt et al., 2007). The onboard battery is used to supply power to tag's sensory elements and other specialised tasks (Lahiri, 2005). Semi-passive tags are a fusion between passive and active tags, which results in increased read ranges (Banks, 2007). Due to their onboard battery and other sensory elements, semi-passive tags are larger than passive tags (see Figure 5). Active tags are used where implementation requires recording environmental characteristics and use of high volume of tags, for example in tracking perishable food transportation (Jedermann et al., 2009).

RFID tags can also be categorised according to the frequency used (see Figure 5). Most commonly used RFID tags utilise the following frequencies: LF (low frequency), HF (high frequency) and UHF (ultra-high frequency), and rarely a microwave frequency (Banks, 2007). Each of the frequencies has different characteristics. Figure 6 presents the effect of different materials on radio frequency waves and tag's performance (Dua and Meyers, 2007; Singh et al., 2009). Environmental impacts on the performance of RFID tags plays a crucial role in choosing the type of tag selected for RFID implementation (Garfinkel \& Rosenberg, 2006). 
Figure 6. Effect of material on radio frequency waves

\begin{tabular}{llcccc}
\hline Material & Effect on RF & LF & HF & UHF & Microwave \\
\hline Cardboard & absorption, detuning & $\mathrm{x}$ & $\mathrm{x}$ & $\mathrm{x}$ & $\mathrm{x}$ \\
Liquid & absorption & $\mathrm{x}$ & $\mathrm{x}$ & & $\mathrm{x}$ \\
Plastic & detuning & $\mathrm{x}$ & $\mathrm{x}$ & $\mathrm{x}$ & \\
Metal & reflection & $\mathrm{x}$ & $\mathrm{x}$ & \\
Human/animal body & absorption, detuning, reflection & $\mathrm{x}$ & $\mathrm{x}$ & \\
\hline
\end{tabular}

\section{RFID READERS}

The second element of the RFID system is the RFID reader, also called the interrogator. An RFID reader is defined as a "device that can read from and write data to compatible RFID tags" (Lahiri, 2005, p. 22). The role of the reader is to communicate with tags within its read range and present gathered tags' data to business applications that can make sense of this information (Banks, 2007).

A typical reader contains the following elements: radio frequency module (transmitter and receiver), control unit, coupling element and communication interface (Finkenzeller, 2010). The radio frequency module transmits power by the reader's antennas throughout its reading zone and receives the response signal back if any tag is within range (Lahiri, 2005). The control unit with a microprocessor and memory storage provides a logic element to the reader, whereas the communication interface is used for exchanging data with an enterprise application (Banks, 2007).

In a similar way to tags, readers also have different shapes and sizes as presented in Figure 7. Depending on the application RFID readers may be a stationary unit in a plastic enclosure, a sturdy stationary module for use in enterprises or a portable hand-held device that includes a mini-computer and display for use by shop-floor workers. In recent years RFID readers have been miniaturised and embedded in mobile phones (Garfinkel and Rosenberg, 2006).

\section{BRIEF HISTORY OF RFID}

The foundations of RFID technology were laid by the Scottish physicist James Clerk Maxwell (18311879) who was a key figure in describing the entity, spread and transmission of electromagnetic waves (Bartneck et al., 2009). His work was further developed by German physicist Heinrich Rudolf Hertz

Figure 7. Example of RFID readers from Alien Technology

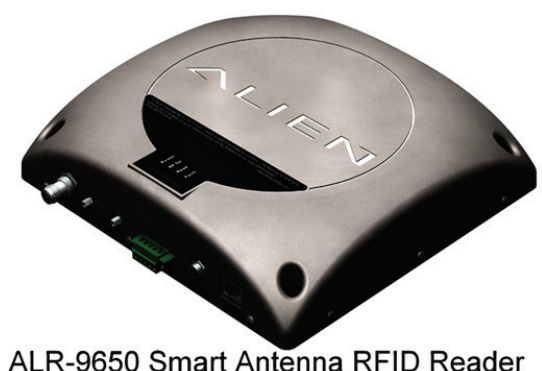

ALR-9650 Smart Antenna RFID Reader

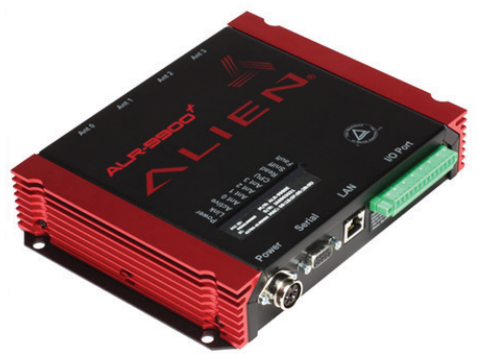

ALR-9900+ Enterprise RFID Reader

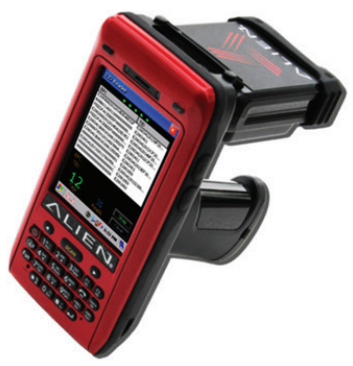

ALH-900x Handheld RFID Reader 
(1875-1894) and Guglielmo Marconi (1874-1937) whose innovations challenged engineers in the twentieth century and beyond (Banks, 2007).

Radio communication, especially advanced during the Second World War, helped solve the problem of identifying returning aircraft in British airspace. The British air force used transponders attached to planes to sent a signal to interrogating base stations, identifying if the plane was a friend or a foe (Domdouzis et al., 2007). After the war this technology was further developed and a publication in October 1948 by Harry Stockman titled "Communications by Means of Reflected Power" is considered foundational to the development of RFID technology as it is known today (Hunt et al., 2007).

Between the 1950s and 1960s the technologies related to RFID were further developed culminating in taking the technology to a wider market with the establishment of three companies, Sensormatic, Checkpoint and Kogo. These companies provided equipment for electronic surveillance of merchandise (Domdouzis et al., 2007). About this time, the introduction of RFID to tagging also allowed the monitoring nuclear materials by the U.S. Government (Garfinkel and Rosenberg, 2006).

The 1970s are described as a period of "RFID Explosion and Early-Adopter Applications" (Hunt et al., 2007) with the development in 1972 of the RFID based access control by Schlage Electronics company and the release of RFID research to the public by Los Alamos Scientific Laboratory in 1977 (Garfinkel \& Rosenberg, 2006).

Increased availability of RFID research through this period led to the exploration of new uses of RFID in the 1980s, such as animal tagging, garage door openers and toll collection on motorways (Garfinkel \& Rosenberg, 2006; Hunt et al., 2007). At this point all new emerging applications of RFID were proprietary systems without any cooperation between the vendors (Hunt et al., 2007).

During the 1990s RFID technology entered the mainstream with many companies such as Philips, Mikron, Alcatel, and Bosch becoming involved in developing RFID technology (Garfinkel \& Rosenberg, 2006; Hunt et al., 2007). During the 1990s steps were taken to standardise RFID technology as a lack of standards was considered to be a significant hindrance to further development (Hunt et al., 2007). In 1999 the Uniform Code Council, EAN International, Procter \& Gamble and Gillette established the Auto-ID Centre at the Massachusetts Institute of Technology (Violino, 2005). According to Bartneck et al. (2009) the opening of Auto-ID Centre opened a new chapter in the history of RFID, which led to the expansion of RFID technology in the 21 st century.

Up to now RFID technology has been successfully applied in many areas of business and E-Commerce, including: manufacturing, distribution and logistics, warehousing, cattle ranching, marine terminal operations, military, retail, document tracking, security access, and healthcare (Banks, 2007; Garfinkel \& Rosenberg, 2006). With the number of academic publications related to RFID on the increase (Lim et al., 2013; Ngai et al., 2008) and growing interest in the idea of "Internet of Things" (Atzori et al., 2010) more applications of RFID into new areas of E-Commerce may be expected in the future.

\section{AUTO-ID SYSTEMS, RFID VS. BARCODE}

As it was mentioned in the introduction, RFID is one of the Automatic Identification and Data Capture (AIDC) technologies (Wamba \& Boeck, 2008). Currently, the most important AIDC technologies include: barcode system, biometric, optical character recognition (OCR), smart cards and lastly RFID. These AIDC technologies are presented in Figure 8, which also indicates (arrow) the relationship between smart cards and RFID as they both have some similar characteristics (Finkenzeller, 2010). This section briefly presents AIDC technologies and contrasts the various characteristics of RFID and barcodes. 
Figure 8. AIDC technologies

Based on Finkenzeller (2010).

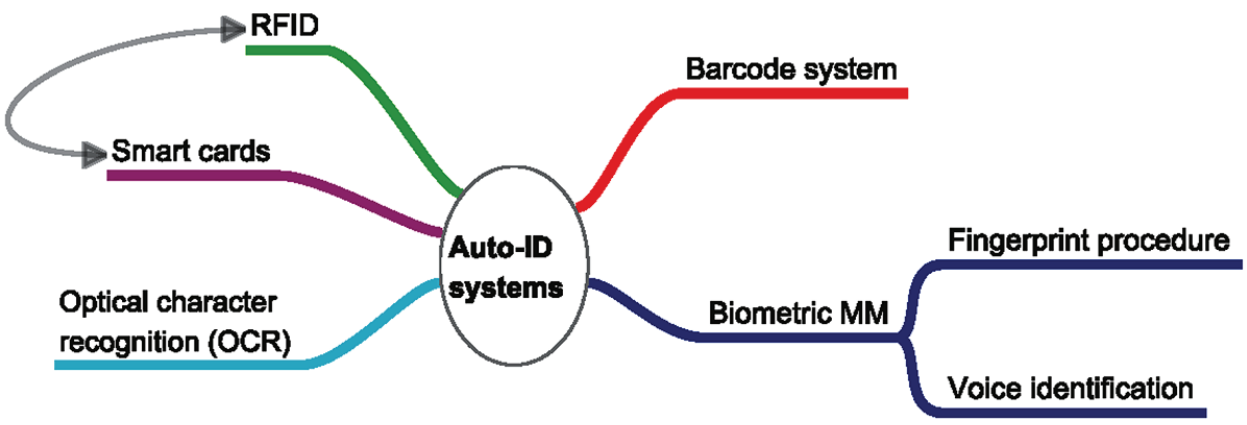

Within AIDC technologies, biometrics encompass all procedures that identify living beings (most commonly humans) by their individual physical characteristics (Finkenzeller, 2010). Common characteristics that identify humans include scanning fingerprints, hand-prints, voice identification and retina scans. Biometrics have a high cost of implementation and very low reading speeds, but have the benefit of restricting unauthorised modifications (Finkenzeller, 2010). Biometrics are commonly used in law enforcement applications, such as criminology and border control (Finkenzeller, 2010).

AIDC technology involves optical charater recognition (OCR) at the core of which lies the principle of making human readable text readable automatically by a machine (Finkenzeller, 2010). Common applications of OCR include administrative fields, banking (i.e. cheques processing), postal systems (i.e scanning destination addresses) and traffic enforcement (i.e. reading car number plates). OCR is characterised by low data density and since it is text, it is easy to read data by human operators (Finkenzeller, 2010).

Smart cards are defined as "electronic data storage systems with additional computing capacity" (Finkenzeller, 2010, p. 4). Typical uses for smart cards include: financial transactions (i.e. debit/credit cards), telephone cards, and smart cards for mobile phones (Finkenzeller, 2010). Smart cards share some characteristics with RFID tags (Finkenzeller, 2010), as both have very high data capacity and density. Data stored on both smart card and RFID tags are inaccessible to humans, making them nearly impossible for unauthorised modifications. Lastly both smart cards and RFID tags are not easily influenced by harsh environments (Finkenzeller, 2010).

Barcodes are the most successful and recognisable AIDC technology (Finkenzeller, 2010). Barcodes are defined as "a scheme in which printed symbols represent textual information" (Lahiri, 2005, p. 114) and operate in binary code made of parallel bars and gaps (Finkenzeller, 2010). Barcodes are typically printed on paper, packaging, or adhesive labels (Lahiri, 2005). An example of a barcode is presented in Figure 9 (on the left), which shows encoding of a book ISBN code. Barcodes are scanned with laser scanners (Finkenzeller, 2010), but in recent years the emergence of the use of cameras in mobile phones to read barcodes has evolved (Ohbuchi et al., 2004). Barcodes give the benefit of fast and accurate data collection leading to increased operational efficiency and reductions in operational costs (Lahiri, 2005). Barcodes are typically used in fields with safety requirements such as medical or clinical applications, logistics for cargo/product identification, retail, libraries, etc. (Finkenzeller, 2010).

Despite their popularity, barcodes have several drawbacks (Ahlund, 2005; Bartneck et al., 2009; Dua \& Meyers, 2007; Hunt et al., 2007; Lahiri, 2005). Firstly, barcodes can be easily soiled, tarnished, torn, fade out or be affected by moisture. Secondly, barcodes need to be in the line of sight of the scanner and be correctly positioned. Thirdly, environment conditions affect the reading accuracy of barcodes, for 
Figure 9. Example of typical barcode and QR code

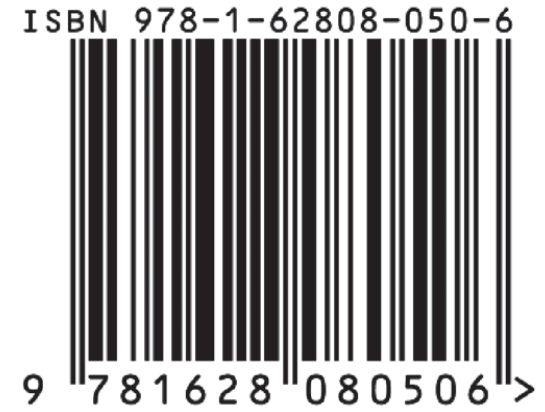

Barcode with book ISBN code.

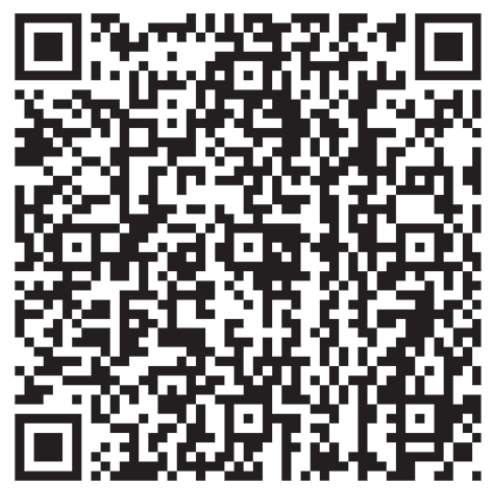

QR code that contains phrase: RFID is an abbreviation for Radio Frequency Identification and as the name implies it is a technology that transmits information through radio waves.

example dampness. Lastly, barcodes can be read only within certain parameters of speed and only one barcode can be scanned at a time.

In order to alleviate some of these drawbacks and increase data density of barcodes, new types of barcodes were developed, such as: Code 128, PDF417, Aztec Code, DataMatrix, MaxiCode and in recent years the QR Code (Lahiri, 2005; Soon, 2008). QR Codea are a matrix symbol, which was developed in 1994 by Denso, part of the Toyota group of companies, and combines high capacity of PDF417, high density of DataMatrix and fast reading of MaxiCode (Soon, 2008). An example of a QR code is shown on the right side of Figure 9. QR Codes are applied in areas like: retail, logistics, public transport (i.e. tickets), hospitality management, patient identification, and marketing (i.e. website encoded as QR Code) (Soon, 2008).

The emergence of RFID as part of AIDC technologies resulted in inevitable comparisons between RFID technologies and barcodes (Ahlund, 2005; Bartneck et al., 2009; Dua and Meyers, 2007; Hunt et al., 2007; Lahiri, 2005). RFID was promoted as a possible barcode replacement (Wu et al., 2006), as it has several advantages over barcodes. A summary of RFID and barcode characteristics is presented in Table 1, based on following works: Ahlund (2005); Dua and Meyers (2007); Hunt et al. (2007); Lahiri (2005).

Key differences between barcode scanning and RFID scanning is indicated on website www.RFIDarena. com (see Figure 10). The author draws similarities between scanning and fishing, with fishermen using a fishing rod, which represents barcode scanning, fishing net representing the RFID scanning, and fish representing objects. Barcode scanning identifies only a single object at a time, whereas RFID allows for simultaneous scans and identification of many objects at the same time.

Another important advantage of RFID over barcodes is that no line of sight is required between reader and RFID tag. Moreover, the position of the scanned item and orientation of tag on the item is not important, whereas a barcode requires correct orientation. Furthermore, RFID technology allows for unique identification of items, as opposed to only category identification offered by barcode. RFID tags are also dynamic, which means their content can be securely changed in the tag writing process, while barcodes are static and have lower data storage capacity than RFID tags. The environmental susceptibility of RFID tags is higher and they can be used in harsh environments, as opposed to barcodes which are difficult to scan when soiled. Lastly, RFID technology offers higher security than barcodes combined with longer reading range. 
Table 1. RFID vs barcode

\begin{tabular}{|l|l|l|}
\hline \multicolumn{1}{|c|}{ Characteristic } & \multicolumn{1}{c|}{ RFID } & \multicolumn{1}{c|}{ Barcode } \\
\hline Position reader & No line of sight required & Line of sight required \\
\hline Identification depth & Uniquely identified items & Identifies only item category \\
\hline Position of scanned item & Item orientation to reader not Important & Requires proper orientation \\
\hline Simultaneous scans & Simultaneous identification of many items & Scans only single item at a time \\
\hline Data updates & Dynamic read/write capability & No write capability, static information \\
\hline Environmental susceptibility & Can be used in harsh environments & Soiled labels difficult to read \\
\hline Memory/data size & More data storage capacity & Limited data storage capacity \\
\hline Standardization & Worldwide standards still in process & Worldwide standards in place \\
\hline Price & More expensive: $\$ 0.10$-plus cost to attach & Cheaper to produce: $\$ 0.001$ \\
\hline Attaching process & $\begin{array}{l}\text { Currently requires two steps: tag creation and } \\
\text { tag attachment }\end{array}$ & $\begin{array}{l}\text { Single step: can be easily printed on boxes } \\
\text { during manufacturing }\end{array}$ \\
\hline Data transmission & Electromagnetic & Optical \\
\hline Access security & High & Low \\
\hline Read range & Centimeters to meters, depending on system & Up to several meters, within line of sight \\
\hline
\end{tabular}

Figure 10. Barcode scanning vs RFID scanning Source: Säilä (2013).

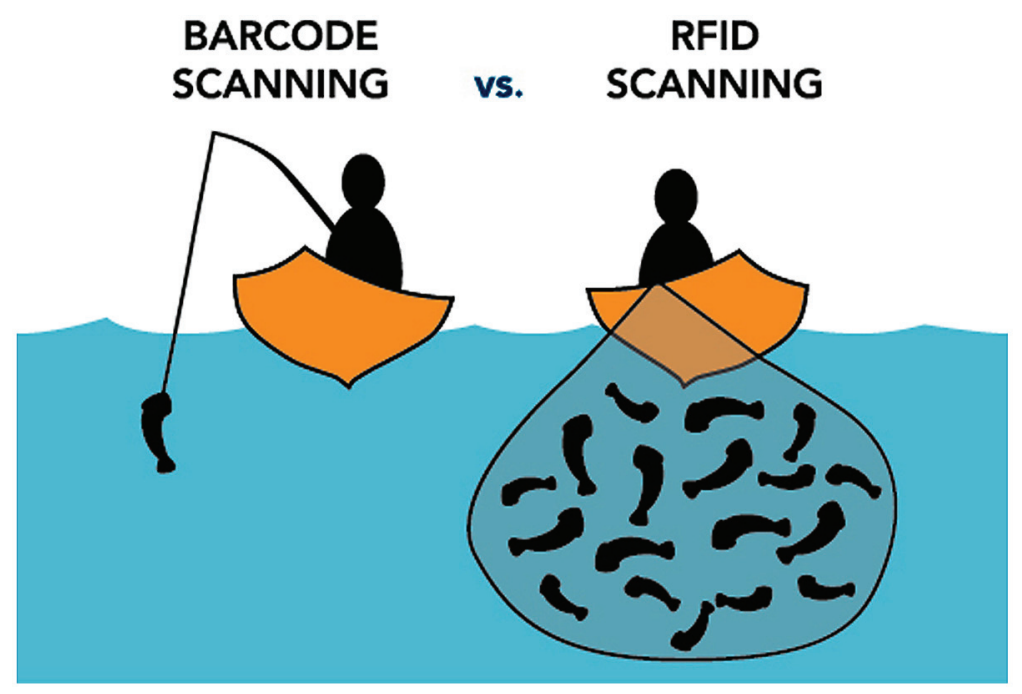

Due to its characteristics and advantages over other AIDC technologies, RFID is increasingly being applied in many different areas including E-Commerce, which is discussed in the next section.

\section{RFID APPLICATIONS: FROM INDUSTRIAL TO E-COMMERCE}

Since 1995, and especially after RFID mandates from the American Ministry of Defence and the American retailer WalMart, the number of applications of RFID technology in a wide range of sectors has systematically increased (Lim et al., 2013; Ngai et al., 2008). 
Chao et al. (2007) state that the main focus of RFID applications is identification of objects or persons. There are however different ways of realising identification in industrial or service sector settings.

Industrial and E-Commerce applications of RFID include: retail, logistics, construction, manufacturing, health care, the pharmaceutical industry and animal detection (Banks, 2007; Domdouzis et al., 2007; Lim \& Winsper, 2012).

RFID technology has been applied in the retail industry in several ways. Firstly, in the apparel industry RFID tags are typically attached to individual garments and in the early stages of RFID adoption were used only for theft prevention (Banks, 2007). Recently, applications of RFID in the apparel industry provide supply chain visibility, inventory management and on shelf availability (Lim \& Winsper, 2012). Secondly, in food retail RFID is used to enhance food safety standards, track shelf life, provide traceability and manage inventory (Lim \& Winsper, 2012). Lastly, RFID technology provides the beverage industry with the possibility of making operational improvements, improving stock visibility, shrinkage prevention and alcohol pouring control (Lim \& Winsper, 2012). Examples of RFID applications in retail and E-Commerce include: apparel tracking in the men's department at Galeria Kaufhof (Thiesse et al., 2009), traceability systems used by producers of Parmigiano Reggiano (the famous Italian cheese) (Regattieri et al., 2007) and the proposition of a glass refill system based on RFID technology (Bhattacharyya et al., 2010).

Developments in RFID technology have been enthusiastically received by logistics practitioners especially due to new demands posed by increases in E-Commerce activities - (Jones \& Chung, 2010) and applied in various areas of logistics including: supply chain visibility (Delen et al., 2007), inventory control and management (Domdouzis et al., 2007; Finkenzeller, 2010), pallet tracking (Chow et al., 2006), container management (Ngai et al., 2007), and tracking returnable transit items (Hellström, 2009).

The construction industry is a challenging and harsh environment which demands AIDC technologies be able to withstand these conditions. Studies have found RFID to be especially suited for the construction industry due to its long reading range and durability (Ergen \& Akinci, 2007). Examples of RFID applications in construction include: concrete processing and handling, cost coding for labour and equipment, and materials control (Jaselskis et al., 1995). Furthermore, tracking pipe spools, identification of pipe-work joints, tracking structural steel parts, valuable asset tracking (theft prevention) and location of buried assets may be also achieved with RFID (Domdouzis et al., 2007).

Manufacturing is another area with increased interest in RFID applications (Lim \& Winsper, 2012). In manufacturing RFID is used for real-time parts and tool location (Domdouzis et al., 2007; Huang et al., 2008), material visibility (Lu et al., 2006), inventory control (Banks, 2007) and tracking items through production processes (Brewer et al., 1999).

Health care and pharmaceutical industries have also benefited from the use of RFID technology (Banks, 2007; Li et al., 2006; Lim \& Winsper, 2012). Examples of applications of RFID in health care include tracking assets in hospitals (Hakim et al., 2006), tracking patients and visitors (Wang et al., 2006), tracking environmental factors of transported blood bags (Domdouzis et al., 2007; Kim et al., 2007). The pharmaceutical industry typically uses RFID for tracking high value drugs (Lim \& Winsper, 2012) and attempts have been made to automate and track drug dispensing to patients (Lahtela et al., 2008; Shieh et al., 2008).

RFID applications in animal detection are fairly mature (Banks, 2007; Li et al., 2006) and examples include cattle ranching (Swedberg, 2008; Voulodimos et al., 2010) and RFID tagging of domestic animals for purpose of tracking and veterinary management (Garfinkel et al., 2005).

RFID technology is also increasingly being applied in both service and public sectors (Lim \& Winsper, 2012). The service sector, especially the leisure and tourism industry, uses RFID for access control, 
payments collection and prevention of counterfeit tickets (Finkenzeller, 2010; Lim \& Winsper, 2012; Oztaysi et al., 2009). Additionally RFID is increasingly used for tracking children at amusement parks, thus preventing them from being lost (Li et al., 2006; Lin et al., 2010). Public sector applications of RFID include tracking library collections (Boss, 2003), providing customised museum tours and information guides (Hsi \& Fait, 2005; Huang et al., 2011), and collecting public transport payments (Banks, 2007; Lim \& Winsper, 2012).

RFID technology provides numerous benefits for a wide range of applications from industrial to ECommerce. These benefits are discussed in the next section.

\section{RFID BENEFITS IN E-COMMERCE}

The widespread deployment of RFID technology depends on the benefits that are perceived and achieved by its application (Whitaker et al., 2007). Lahiri (2005) defines the benefits of RFID as the advantages that come from the characteristics of the product as they exist today. According to this definition RFID advantages over other AIDC technologies include: contactless, writeable data, readings without line of sight, short and long read ranges, multi-tag reading, ruggedness and durability of tags, and the ability to measure environmental conditions (Lahiri, 2005).

Other authors perceive the benefits of RFID in terms of its technological value in particular applications. For instance Dutta et al. (2007) asserts that the value of RFID is derived from applications that provide a company with labour cost savings, reduced shrinkage and increased product visibility. Similarly, Tajima (2007) discusses general RFID benefits in the supply chain and in particular the benefits applicable to each tier. General benefits include: reduced material handling, increased data accuracy, faster exception management, improved information sharing and the aforementioned reduced shrinkage (Tajima, 2007). Particular benefits include for manufacturing: production tracking, quality control and supply, and production continuity; for logistic providers: material handling, improved space utilisation, asset management; and lastly for retailers: reduced stockouts, lower inventory, and better customer and aftersales services (Tajima, 2007). These benefits are also applicable to E-Commerce.

A recent publication by Lim et al. (2013) comprehensively analysed benefits provided by RFID technology and although the authors narrowly focused on warehousing, the list of benefits of RFID is also applicable to E-Commerce. See Table 2.

The research community is called upon by Lee et al. (2007) to provide more substantial analysis and have a more balanced view of RFID despite its numerous benefits. Hence, the next section is focused on the difficulties of RFID technology implementation in E-Commerce.

\section{OBSTACLES TO SUCCESSFUL APPLICATIONS OF RFID IN E-COMMERCE}

Bahr and Lim (2009) and Lim et al. (2013) point out five obstacles to successful implementation of RFID systems, all of them relevant to E-Commerce:

- Uncertain return on investment;

- Integration with legacy systems;

- $\quad$ Failing RFID performance;

- Concerns about privacy and security;

- Standards development. 
Table 2. RFID benefits in e-commerce

\begin{tabular}{|c|c|}
\hline Benefit Category & Benefits \\
\hline Product/Resource related & $\begin{array}{l}\text { - Reduced shrinkage } \\
\text { - Product tracking } \\
\text { - Space utilisation } \\
\text { - Asset/resource management } \\
\text { - Reduced stockouts } \\
\text { - Lower inventory } \\
\text { - Better expiry date management }\end{array}$ \\
\hline Operational & $\begin{array}{l}\text { - Reduced material handling } \\
\text { - Faster exception management } \\
\text { - Quality control } \\
\text { - Supply and production continuity } \\
\text { - Better customer service } \\
\text { - Reduced labour } \\
\text { - Lower costs } \\
\text { - After sale services } \\
\text { - Reduction in unofficial supply chains (counterfeit prevention) }\end{array}$ \\
\hline Informational & $\begin{array}{l}\text { - Increased data accuracy } \\
\text { - Improved information sharing in supply chain } \\
\text { - Better determining of arrival/despatch times } \\
\text { - Tags can contain more information and be updated }\end{array}$ \\
\hline
\end{tabular}

Return on investment (ROI) is one of the most crucial criteria for companies to consider when introducing a new technology, as this will point to their expectation on quantifiable benefits Collins (2004). Industry leaders indicated their lack of trust in RFID in providing a satisfactory ROI (Attaran, 2007; O'Connor, 2005; Vijayaraman \& Osyk, 2006; White et al., 2008). In order to justify an acceptable ROI for RFID implementation in E-Commerce, academics and professionals should look into the benefits of the RFID as provided by Lim et al. (2013).

The need for integration with legacy systems such as WMS, Enterprise Resource Planning (ERP), and Customer Relationship Management (CRM), is indicated by Vijayaraman and Osyk (2006). However, integration of RFID even with very old IT systems is possible (Fleet, 2004). Seamless integration of systems is a great challenge, but it has the possibility to provide significantly benefits to a wide range of E-Commerce business activities.

Limited RFID performance was indicated by several studies on RFID (Bosselmann \& Rembold, 2006; Kabadurmus et al., 2007; Porter et al., 2004; Singh et al., 2009; Wu et al., 2006). These and similar studies may have impacted the perception of RFID as unreliable, despite claims from RFID vendors claiming 100\% reading accuracy (Swedberg, 2009). Perceptions of poor performance from earlier RFID experiences among practitioners may need time to overcome.

Concerns about privacy and security are especially expressed by the general public, which understands RFID to track people and objects anywhere and anytime (Hardgrave \& Miller, 2006). There are also concerns about unauthorised reading of data (Roussos \& Kostakos, 2009) and threats of job security (Curtin et al., 2007). These issues may be resolved by increasing the protection measures embedded in the RFID hardware and software, while public privacy concerns about RFID may be alleviated by education and legislation.

Standards development has been an issue since the early years of RFID and is the key issue for future growth of this technology (Vijayaraman \& Osyk, 2006). Nowadays existing RFID standards are more established (Finkenzeller, 2010) and RFID vendors are currently complying with Gen-2 standard in or- 
der to promote wider interoperability. However, some vendors are still using their proprietary protocols for specific purposes/applications. In addition, power regulations and certification procedures are still varied from country to country.

\section{CONCLUSION}

This chapter presented RFID technology and its application, benefits, and obstacles in E-Commerce. Although adoption of RFID today is not as widespread as was previously predicted, there is a consistent growth of this technology. There are distinct benefits to E-Commerce from the use of the RFID, especially as the Internet of Things and Big Data become an increasing reality and customers become more familiar with these technologies.

\section{REFERENCES}

Ahlund, M. (2005, April). RFID in the biopharmaceutical supply chain. BioPharm International Magazine, 1 .

Arnall, T. (2007). RFID tags. Retrieved from http://www.flickr.com/photos/timo/1616057288/

Attaran, M. (2007). RFID: An enabler of supply chain operations. Supply Chain Management: An International Journal, 12(4), 249-257. doi:10.1108/13598540710759763

Atzori, L., Iera, A., \& Morabito, G. (2010). The internet of things: A survey. Computer Networks, 54(15), 2787-2805. doi:10.1016/j.comnet.2010.05.010

Bahr, W. and Lim, M. K. (2009). Implementation challenges of application of radio frequency identification (RFID) in warehouse. Academic Press.

Banks, J. (2007). RFID applied. Wiley. doi:10.1002/9780470168226

Bartneck, N., Klaas, V., \& Schönherr, H. (2009). Optimizing Processes with RFID and Auto ID. Publicis.

Bhattacharyya, R., Floerkemeier, C., \& Sarma, S. (2010). RFID tag antenna based sensing: does your beverage glass need a refill? In RFID, 2010 IEEE International Conference on, (pp. 126-133). IEEE. doi:10.1109/RFID.2010.5467235

Boss, R. W. (2003). RFID technology for libraries. American Library Association.

Bosselmann, P., \& Rembold, B. (2006). Investigations on uhf RFID wave propagation using a ray tracing simulator. Frequenz, 60(3-4), 38-46. doi:10.1515/FREQ.2006.60.3-4.38

Brewer, A., Sloan, N., \& Landers, T. L. (1999). Intelligent tracking in manufacturing. Journal of Intelligent Manufacturing, 10(3-4), 245-250. doi:10.1023/A:1008995707211

Chao, C.-C., Yang, J.-M., \& Jen, W.-Y. (2007). Determining technology trends and forecasts of RFID by a historical review and bibliometric analysis from 1991 to 2005. Technovation, 27(5), 268-279. doi:10.1016/j.technovation.2006.09.003 
Chow, H. K., Choy, K. L., Lee, W., \& Lau, K. (2006). Design of a RFID case-based resource management system for warehouse operations. Expert Systems with Applications, 30(4), 561-576. doi:10.1016/j. eswa.2005.07.023

Collins, J. (2004). RFID's ROI tops user concerns. RFID Journal, 26.

Curtin, J., Kauffman, R. J., \& Riggins, F. J. (2007). Making the most out of RFID technology: A research agenda for the study of the adoption, usage and impact of RFID. Information Technology Management, 8(2), 87-110. doi:10.1007/s10799-007-0010-1

Delen, D., Hardgrave, B. C., \& Sharda, R. (2007). RFID for better supply-chain management through enhanced information visibility. Production and Operations Management, 16(5), 613-624. doi:10.1111/j.1937-5956.2007.tb00284.x

Domdouzis, K., Kumar, B., \& Anumba, C. (2007). Radio-frequency identification (RFID) applications: A brief introduction. Advanced Engineering Informatics, 21(4), 350-355. doi:10.1016/j.aei.2006.09.001

Dua, S., \& Meyers, M. (2007). Mike Meyers' Comptia RFID+Certification Passport. McGraw-Hill, Inc.

Dutta, A., Lee, H. L., \& Whang, S. (2007). RFID and operations management: Technology, value, and incentives. Production and Operations Management, 16(5), 646-655. doi:10.1111/j.1937-5956.2007. tb00286.x

Ergen, E., \& Akinci, B. (2007). An overview of approaches for utilizing RFID in construction industry. In RFID Eurasia, 2007 1st Annual (pp. 1-5). IEEE. doi:10.1109/RFIDEURASIA.2007.4368087

Finkenzeller, K. (2010). RFID handbook: fundamentals and applications in contactless smart cards, radio frequency identification and near-field communication (3rd ed.). Hoboken, NJ: Wiley. doi:10.1002/9780470665121

Fleet, S. (2004). Case study: international paper. RFID Journal.

Garfinkel, S., \& Rosenberg, B. (2006). RFID: Applications, security, and privacy. Pearson Education.

Garfinkel, S. L., Juels, A., \& Pappu, R. (2005). RFID privacy: An overview of problems and proposed solutions. Security \& Privacy, IEEE, 3(3), 34-43. doi:10.1109/MSP.2005.78

Hakim, H., Renouf, R., \& Enderle, J. (2006). Passive RFID asset monitoring system in hospital environments. In Bioengineering Conference, 2006. Proceedings of the IEEE 32nd Annual Northeast, (pp. 217-218). IEEE. doi:10.1109/NEBC.2006.1629830

Hardgrave, B., \& Miller, R. (2006). The myths and realities of RFID. International Journal of Global Logistics \& Supply Chain Management, 1(1), 1-16.

Hellström, D. (2009). The cost and process of implementing RFID technology to manage and control returnable transport items. International Journal of Logistics: Research and Applications, 12(1), 1-21. doi:10.1080/13675560802168526

Hsi, S., \& Fait, H. (2005). RFID enhances visitors' museum experience at the exploratorium. Communications of the ACM, 48(9), 60-65. doi:10.1145/1081992.1082021 
Huang, G. Q., Zhang, Y., \& Jiang, P. (2008). RFID-based wireless manufacturing for real-time management of job shop wip inventories. International Journal of Advanced Manufacturing Technology, 36(7-8), 752-764. doi:10.1007/s00170-006-0897-4

Huang, Y.-P., Wang, S.-S., \& Sandnes, F. E. (2011). RFID-based guide gives museum visitors more freedom. IT Professional, 13(2), 25-29. doi:10.1109/MITP.2011.33

Hunt, V. D., Puglia, A., \& Puglia, M. (2007). RFID: a guide to radio frequency identification. John Wiley \& Sons. doi:10.1002/0470112255

Jaselskis, E. J., Anderson, M. R., Jahren, C. T., Rodriguez, Y., \& Njos, S. (1995). Radio-frequency identification applications in construction industry. Journal of Construction Engineering and Management, 121(2), 189-196. doi:10.1061/(ASCE)0733-9364(1995)121:2(189)

Jedermann, R., Ruiz-Garcia, L., \& Lang, W. (2009). Spatial temperature profiling by semi-passive RFID loggers for perishable food transportation. Computers and Electronics in Agriculture, 65(2), 145-154. doi:10.1016/j.compag.2008.08.006

Jones, E. C., \& Chung, C. A. (2010). RFID in logistics: a practical introduction. CRC press.

Kabadurmus, O., Kilinc, S., Behret, H., \& Uygun, G. (2007). Performance evaluation of operational parameters on RFID controlled conveyor system. In RFID Eurasia, 2007 1st Annual (pp. 1-6). IEEE. doi:10.1109/RFIDEURASIA.2007.4368143

Kim, D.-S., Yoo, S., Kim, H., Chang, B., Bae, H., \& Kim, S. (2007). Location based blood bag management using active RFID and ubiquitous sensor network. In Information Technology Applications in Biomedicine, 2007. ITAB 2007. 6th International Special Topic Conference on, (pp. 320-322). IEEE. doi:10.1109/ITAB.2007.4407413

Lahiri, S. (2005). RFID sourcebook. IBM Press.

Lahtela, A., Hassinen, M., \& Jylha, V. (2008). RFID and nfc in healthcare: Safety of hospitals medication care. In Pervasive Computing Technologies for Healthcare, 2008. PervasiveHealth 2008. Second International Conference on, (pp. 241-244). IEEE.

Lee, H., \& Ozer, O. (2007). Unlocking the value of RFID. Production and Operations Management, 16(1), 40-64. doi:10.1111/j.1937-5956.2007.tb00165.x

Li, S., Visich, J. K., Khumawala, B. M., \& Zhang, C. (2006). Radio frequency identification technology: Applications, technical challenges and strategies. Sensor Review, 26(3), 193-202. doi:10.1108/02602280610675474

Lim, M. K., Bahr, W., \& Leung, S. (2013). RFID in the warehouse: A literature analysis (1995-2010) of its applications, benefits, challenges and future trends. International Journal of Production Economics.

Lim, M. K., \& Winsper, M. (2012). Exploring value-added applications of RFID systems in industry and service sectors. In Information Science and Digital Content Technology (ICIDT), 2012 8th International Conference on, (vol. 2, pp. 470-475). IEEE.

Lin, X., Lu, R., Kwan, D., \& Shen, X. S. (2010). React: An RFID-based privacy-preserving children tracking scheme for large amusement parks. Computer Networks, 54(15), 2744-2755. doi:10.1016/j. comnet.2010.05.005 
Lu, B., Bateman, R., \& Cheng, K. (2006). RFID enabled manufacturing: Fundamentals, methodology and applications. International Journal of Agile Systems and Management, 1(1), 73-92. doi:10.1504/ IJASM.2006.008860

Ngai, E., Moon, K. K., Riggins, F. J., \& Yi, C. Y. (2008). RFID research: An academic literature review (1995-2005) and future research directions. International Journal of Production Economics, 112(2), 510-520. doi:10.1016/j.ijpe.2007.05.004

Ngai, E. W., Cheng, T. E., Au, S., \& Lai, K.-. (2007). Mobile commerce integrated with RFID technology in a container depot. Decision Support Systems, 43(1), 62-76. doi:10.1016/j.dss.2005.05.006

Ni, L. M., Liu, Y., Lau, Y. C., \& Patil, A. P. (2004). Landmarc: Indoor location sensing using active RFID. Wireless Networks, 10(6), 701-710. doi:10.1023/B:WINE.0000044029.06344.dd

O'Connor, M. C. (2005). Most RFID users believe RFID lacks ROI. RFID Journal.

Ohbuchi, E., Hanaizumi, H., \& Hock, L. A. (2004). Barcode readers using the camera device in mobile phones. In Cyberworlds, 2004 International Conference on, (pp. 260-265). IEEE. doi:10.1109/CW.2004.23

Öztayşi, B., Baysan, S., \& Akpinar, F. (2009). Radio frequency identification (RFID) in hospitality. Technovation, 29(9), 618-624. doi:10.1016/j.technovation.2009.05.014

Porter, J. D., Billo, R. E., \& Mickle, M. H. (2004). A standard test protocol for evaluation of radio frequency identification systems for supply chain applications. Journal of Manufacturing Systems, 23(1), 46-55. doi:10.1016/S0278-6125(04)80006-2

Regattieri, A., Gamberi, M., \& Manzini, R. (2007). Traceability of food products: General framework and experimental evidence. Journal of Food Engineering, 81(2), 347-356. doi:10.1016/j.jfoodeng.2006.10.032

Roussos, G., \& Kostakos, V. (2009). RFID in pervasive computing: State-of-the-art and outlook. Pervasive and Mobile Computing, 5(1), 110-131. doi:10.1016/j.pmcj.2008.11.004

Säilä, J. (2013). 6 most common faqs of barcode vs RFID. Retrieved from http://www.RFIDarena. com/2013/12/2/6-most-common-faqs-of-barcode-vs-RFID.aspx

Shieh, S., Lin, C., Yang, T., \& Tu, G. (2008). Using RFID technology on clinic's pharmacy operation management and development of intelligent medicine dispensing cabinet. In Industrial Engineering and Engineering Management, 2008. IEEM2008. IEEE International Conference on, (pp. 2006-2009). IEEE.

Singh, J., Olsen, E., Vorst, K., \& Tripp, K. (2009). RFID tag readability issues with palletized loads of consumer goods. Packaging Technology and Science, 22(8), 431-441. doi:10.1002/pts.864

Soon, T. J. (2008). QR code. Synthesis Journal.

Swedberg, C. (2008). Zigbeef offers ranchers a long-distance cattle head count. RFID Journal.

Swedberg, C. (2009). Odin forecasts fast ROI for RFID-based baggage handling. RFID Journal.

Tajima, M. (2007). Strategic value of RFID in supply chain management. Journal of Purchasing and Supply Management, 13(4), 261-273. doi:10.1016/j.pursup.2007.11.001

Thiesse, F., Al-Kassab, J., \& Fleisch, E. (2009). Understanding the value of integrated RFID systems: A case study from apparel retail. European Journal of Information Systems, 18(6), 592-614. doi:10.1057/ ejis. 2009.33 
Vijayaraman, B. S., \& Osyk, B. A. (2006). An empirical study of RFIDimplementation in the warehousing industry. International Journal of Logistics Management, 17(1), 6-20. doi:10.1108/09574090610663400

Violino, B. (2005). The history of RFID technology. RFID Journal.

Voulodimos, A. S., Patrikakis, C. Z., Sideridis, A. B., Ntafis, V. A., \& Xylouri, E. M. (2010). A complete farm management system based on animal identification using RFID technology. Computers and Electronics in Agriculture, 70(2), 380-388. doi:10.1016/j.compag.2009.07.009

Wamba, S. F., \& Boeck, H. (2008). Enhancing information flow in a retail supply chain using RFID and the epc network: A proof-of-concept approach. JTAER, 3(1), 92-105.

Wang, S.-W., Chen, W.-H., Ong, C.-S., Liu, L., \& Chuang, Y.-W. (2006). RFID application in hospitals: a case study on a demonstration RFID project in a Taiwan hospital. In System Sciences, 2006. HICSS'06. Proceedings of the 39th Annual Hawaii International Conference on, (vol. 8, pp. 184a-184a). IEEE.

Whitaker, J., Mithas, S., \& Krishnan, M. (2007). A field study of RFID deployment and return expectations. Production and Operations Management, 16(5), 599-612. doi:10.1111/j.1937-5956.2007.tb00283.x

White, A., Johnson, M., \& Wilson, H. (2008). RFID in the supply chain: Lessons from european early adopters. International Journal of Physical Distribution \& Logistics Management, 38(2), 88-107. doi:10.1108/09600030810861189

Wu, N.-C., Nystrom, M., Lin, T.-R., \& Yu, H.-C. (2006). Challenges to global RFID adoption. Technovation, 26(12), 1317-1323. doi:10.1016/j.technovation.2005.08.012

\section{KEY TERMS AND DEFINITIONS}

Active Tag: Active tag is the RFID tag with an onboard power supply (i.e. battery) and may also include elements for performing specialised tasks (i.e. sensory elements for temperature, humidity, positioning system, etc.). Use of battery in active tag results in longer reading range and increased readability in harsh environments.

AIDC: Automatic Identification and Data Capture technologies, such as: barcode system, biometric, optical character recognition (OCR), smart cards, and RFID.

Barcode: A machine-readable printed symbols representing textual/numerical information. Barcodes are the most popular AIDC technology and are typically used for stock control.

Passive Tag: Passive tag is the RFID tag powered by the means of reflected energy from the reader. Passive tag has a simple construction and their price is significantly cheaper than active tags.

Reader: An RFID reader, also known as an interrogator, receives information from the tag and provides it to the enterprise system. Reader uses one or more antennas to capture information from the tag.

RFID: Radio Frequency Identification (RFID) is one of the AIDC technologies. RFID uses electromagnetic fields to transfer data between tags and readers for the purposes of automatically identifying and tracking tags attached to objects.

Tag: RFID tag can store and transmit data to a reader in a contactless manner using radio waves. Tag consists of: antenna (coupling element), integrated circuit (chip), printed circuit board/substrate (housing). There are active and passive RFID tags. 


\section{Encyclopedia of E-Commerce Development, Implementation, and Management}

In Lee

Western Illinois University, USA

Volume III

Categories: $\mathrm{R}-\mathrm{T}$ 
Published in the United States of America by

Business Science Reference (an imprint of IGI Global)

701 E. Chocolate Avenue

Hershey PA, USA 17033

Tel: 717-533-8845

Fax: 717-533-8661

E-mail: cust@igi-global.com

Web site: http://www.igi-global.com

Copyright (C) 2016 by IGI Global. All rights reserved. No part of this publication may be reproduced, stored or distributed in any form or by any means, electronic or mechanical, including photocopying, without written permission from the publisher. Product or company names used in this set are for identification purposes only. Inclusion of the names of the products or companies does not indicate a claim of ownership by IGI Global of the trademark or registered trademark.

Library of Congress Cataloging-in-Publication Data

Names: Lee, In, 1958- editor.

Title: Encyclopedia of e-commerce development, implementation, and management

/ In Lee, Edito.

Description: Hershey : Business Science Reference, 2016. I Includes

bibliographical references and index.

Identifiers: LCCN 2015043744| ISBN 9781466697874 (hardcover : alk. paper) I

ISBN 9781466697881 (ebook)

Subjects: LCSH: Electronic commerce--Encyclopedias.

Classification: LCC HF5548.32 .E524 2016 I DDC 658.8/7203--dc23 LC record available at http://lccn.loc.gov/2015043744

British Cataloguing in Publication Data

A Cataloguing in Publication record for this book is available from the British Library.

All work contributed to this book is new, previously-unpublished material. The views expressed in this book are those of the authors, but not necessarily of the publisher.

For electronic access to this publication, please contact: eresources@igi-global.com. 
RFID Tagging: An ID system that uses small radio frequency identification devices for identification and tracking purposes. An RFID tagging system includes the tag itself, a read/write device, and a $\mathbf{R}$ host system application for data collection, processing, and transmission.

Supply Chain Management (SCM) System: System that manages the integrated supply chain; process are linked across companies with a companion process at a customer or supplier. 